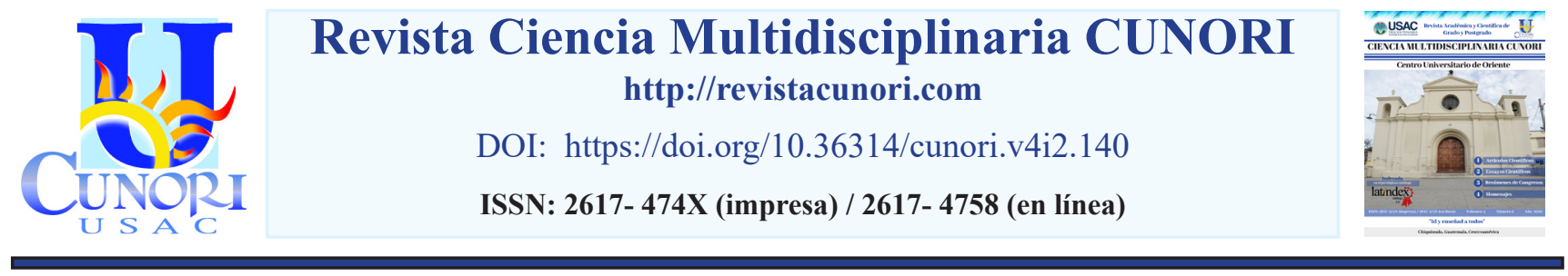

Referencia del ensayo

Aceituno-Ramos, A. H. (2020). Incidencia de la mayéutica en la pedagogía constructivista. Revista Ciencia Multidisciplinaria Cunori, 4(2), 157-162. https://doi.org/10.36314/cunori.v4i2.140

\title{
Incidencia de la mayéutica en la pedagogía constructivista
}

\section{Incidence of mayeutics in constructivist pedagogy}

\author{
Axel Hernaldo Aceituno Ramos \\ Universidad de San Carlos de Guatemala \\ https://orcid.org/0000-0001-5296-2584
}

Recibido: 25 de mayo de 2020 / Revisado: 26 de mayo de 2020 / Aceptado: 05 de junio de 2020

Disponible en internet el 30 de octubre de 2020

*Autor para correspondencia.

Correo electrónico: axelaceituno16@profesor.usac.edu.gt

Resumen

T a mayéutica es el método epistemológico propuesto por Sócrates y que consiste básicamente en dar a luz el propio conocimiento, el mismo, posee características que han sido utilizadas por la pedagogía, principalmente por la teoría constructivista del aprendizaje por descubrimiento de Jerome Bruner. En este artículo se realiza una breve comparación entre ambas propuestas para señalar la incidencia y presencia que posee la filosofía, por medio de la mayéutica en la pedagogía constructivista.

Palabras clave: mayéutica, pedagogía, constructivismo

\section{Abstract}

$\mathrm{T}$ he Mayeutic was an epistemological method proposed by Socrates and which basically consisted in giving birth to one's own knowledge, it has characteristics that have been used by pedagogy, mainly by the constructivist theory of discovery learning by Jerome Bruner. In this article, a brief comparison is made between both proposals to indicate the incidence and presence that philosophy possesses, by means of the Mayeutic in the constructivist Pedagogy.

Keywords: mayeutic, pedagogy, constructivism 


\section{Introducción}

La filosofía y la educación han marcado el ritmo por el cual se mueve el ser humano. Es por ello que es relevante conocer la relación existente entre la filosofía y la educación, debido a que la mayor parte de los métodos pedagógicos, se han fundamentado en los métodos filosóficos; aunque en la actualidad se brinde mayor importancia a los aportes psicológicos y neurocientíficos para desarrollar una propuesta metodológica, se siguen desarrollando teorías cuyas características hacen referencia a propuestas filosóficas. Es por ello, que el objetivo del presente trabajo es establecer si existe una relación entre la filosofía socrática y la teoría constructivista del aprendizaje por descubrimiento de Jerome Bruner. Debido a las características que posee el objeto a investigar y la problemática a resolver, se utilizará el método hermenéutico analógico, comparando diversos textos que permitan alcanzar el objetivo propuesto.

Se han encontrado grandes rasgos y características propias del método mayéutico en el ámbito educativo, principalmente en la corriente constructivista, es debido a ello que el presente manuscrito se propone comparar ambas metodologías para sustentar que el entramado propuesto por la pedagogía, ha sido fuertemente apoyado por la filosofía, en cuanto que, por su estructura y contenido, existen muchas características y aspectos metodológicos que la filosofía ya ha propuesto en su momento por diversidad de autores, en sus respectivas épocas, tales como la heurística, el holismo, la lógica, incluso el método científico posee fundamentación filosófica.

La filosofía siempre ha repercutido en la sociedad y no solamente se ha hecho presente en las corrientes suscitadas en la Europa Occidental o una época específica, esto significa que posee un carácter atemporal, en cuanto que sus contenidos han sido estudiados y puestos en práctica a través del tiempo y de la historia, tal es el caso de filósofos que han trascendido grandemente como Pitágoras, Sócrates, Santo Tomás, René Descartes, Hume, Husserl, por mencionar algunos; cuyas obras han sido verdaderos baluartes en diversidad de campos científicos, inclusive muchas de las ciencias han sido gestadas en el seno de la filosofía, entre ellas la Pedagogía. Es necesario mencionar que el presente estudio se limitará a comparar exclusivamente el método mayéutico propuesto por Sócrates y la Teoría por descubrimiento del psicopedagogo Jerome Bruner quien pertenece al grupo de pedagogos fundadores de la corriente constructivista.

\section{Origen de la mayéutica}

En Atenas, Grecia, nace un filósofo excepcional llamado Sócrates (469-399 a. C.) cuyo pensamiento ha sido uno de los más profundos de la cultura occidental y la filosofía universal. Procedente de una familia humilde, su padre era escultor y su madre se dice que era partera, detalle que influyó grandemente en su manera de hacer filosofía. Sócrates mencionaba que había heredado el oficio de sus padres, debido a que se había preocupado por esculpir, en el alma de cada individuo, la verdad y la virtud, así como ayudar a dar a luz, en el fondo de cada alma, el conocimiento de sí mismo y sus virtudes. Según Escobar (2011), no dejó ningún testimonio escrito de su pensamiento, ni de sus acciones. Su pensamiento filosófico, así como su vida es conocida gracias a tres fuentes fundamentales: la que nos proporciona Aristófanes en su comedia Las Nubes; la que nos ofrece Platón en sus inmortales diálogos y la que escribe Jenofonte en 
sus Memorias de Sócrates. Es relevante mencionar que en el presente estudio se indagarán únicamente algunos diálogos de Platón, los cuales nos ofrecen importante información acerca del método socrático.

Sócrates estaba convencido que, sin una constante indagación, el descubrimiento de lo que es justo, bueno y virtuoso no sería posible. Así mismo, consideraba que, dentro de cada uno de los seres humanos, había un conocimiento innato que se debía dar a luz. El método idóneo para este descubrimiento le nombró, Mayéutica. Se puede mencionar que la mediación de Sócrates en el perfeccionamiento de los ciudadanos de su Polis consistió en originar cierto interés, en crearles una inquietud interna, en motivarlos para que por sí mismos descubrieran la verdad y así, conocieran la naturaleza de las virtudes hasta donde ello fuera posible. La misión de Sócrates era la de ser un guía, un conductor del diálogo, de esta dialéctica que impulsara la reflexión como una eficaz herramienta para orientar la vida de los ciudadanos griegos.

Para Albarrán (2009), Sócrates creía en el poder de la palabra hablada, por eso su arte u oficio siempre ha sido comparado con el de su madre. Sócrates tenía como oficio dar a luz al conocimiento, porque estaba totalmente convencido que, gracias al método mayéutico, se podría llegar a una idea clara de las cosas y a una doctrina moral que orientara y regulara la convivencia social, sin embargo (Albarrán Vásquez, 2009, pág. 19) expresa “mi arte de partear tiene las mismas características que el de ellas, pero se diferencia en el hecho de que asiste a los hombres y no a las mujeres, y examina las almas de los que dan a luz, pero no sus cuerpos. Ahora bien, lo más grande que hay en mi arte es la capacidad e que tiene de poner a prueba por todos los medios si lo que engendra el pensamiento del joven es algo imaginario y falso o fecundo y verdadero" (Platón, Diálogos V, 1988, pág. 189).

Entre las principales características de este método, pueden mencionarse en primer lugar, el rol del maestro es un papel de mediador, de facilitador del conocimiento, debido a que únicamente debía intermediar; no era quien proporcionaba el saber, era únicamente el que ayudaba a cada alumno a alcanzar la verdad. Así mismo, el rol del discípulo radicaba en que debía resolver sus propias interrogantes, Sócrates consideraba que eran capaces de ello, debido a que mencionaba la existencia de un conocimiento dentro de sí el cual debe escudriñar cada quien; el discípulo no era un simple receptor de conocimiento. Entre las características primordiales en su metodología se encuentran, el diálogo, la interrogación, la investigación, el análisis de parte del discípulo y la resolución de problemas por sí mismo "y si alguno de vosotros me lo niega y dice que sí, que se cuida, no me separaré de él tan pronto, no me iré, no, sino que lo interrogaré, que lo examinaré, que le confundiré; y si veo que no es virtuoso, bien que lo presume, le reprenderé por tener en menos estima lo que vale más y en más lo que vale menos. Eso es lo que haré con cualquiera que encuentre, joven o viejo, ciudadano o extranjero, pero sobre todo con vosotros que me tocáis de más cerca; porque sabedlo bien, eso es lo que el Dios me ordena" (Platón, Apología de Sócrates, 1990, pág. 56).

Bucheti (2008), con respecto al método mayéutico menciona: “es por ello, que el significado etimológico del vocablo "mayéutica" tomado del griego, se relaciona con las parteras u obstetras que ayudan a dar a luz a las parturientas. De la misma manera, Sócrates contribuía, con sus discípulos, para que dieran 
a luz, a las verdades desconocidas e inconscientes que se encontraban en lo más profundo de su ser. La mayéutica consistía en el empleo del diálogo para alcanzar el verdadero conocimiento. Mediante el diálogo y a través de un trato muy personalizado con su discípulo, Sócrates, le ayudaba a que alcanzara por sí mismo el saber.” (Bucheti, 2008, págs. 82-83).

\section{La teoría constructivista del aprendizaje por descubrimiento}

Cuando se realiza un análisis comparativo entre la educación y la filosofía, se puede observar que diversos métodos de enseñanza han tomado en cuenta o se han fundamentado en métodos filosóficos, han extraído y adoptado al ámbito educativo, diversas características que se han utilizado en la filosofía. Desde esta perspectiva es necesario mencionar que, dentro de la pedagogía, la corriente constructivista por su parte ha utilizado técnicas como la observación, la participación, el análisis, la solución de problemas y la construcción del conocimiento. El constructivismo surge como contraparte principalmente del conductismo, el cual formuló metodologías que ahora son conocidas como tradicionales, éstas se fundamentaban principalmente en el uso exagerado de la memoria, de las respuestas mecanizadas y de considerar al estudiante como un receptor del conocimiento que brindaba el maestro, tenía un rol pasivo en la educación, delegando el protagonismo únicamente al maestro, esto sin mencionar el ambiente en el que se desenvolvían, ya que no se consideraba la igualdad, la psicología del color, la inteligencias múltiples, etc. El constructivismo asumiría que nada viene de nada. Es decir que conocimiento previo da nacimiento a conocimiento nuevo. El constructivismo vendría a interpretar que el aprendizaje es esencialmente activo.

Se tuvieron que romper diversos paradigmas en torno a la educación para poder implementar la metodología constructivista; sin embargo, al día de hoy aún existen resquicios de la educación tradicional dentro de los diversos salones de clase en los múltiples niveles académicos. Jerome Bruner, propuso la Teoría del Aprendizaje por descubrimiento, la cual promueve que el estudiante construya su propio conocimiento por medio de la resolución de problemas, del diálogo, de la interactividad con el ambiente y principalmente se fomentan los nuevos roles dentro del aula, debido a que el docente se vuelve un mediador del conocimiento, un facilitador en medio de los problemas planteados y deja atrás el protagonismo que le brindó el conductismo, el dicente por su parte, es un constructor de su propio conocimiento, toma el protagonismo dentro del aprendizaje y se vuelve una pieza clave en el mismo, debido a que ya no será un simple receptor del conocimiento, sino que buscará dentro de sí las respuestas a los problemas planteados.

Bruner (1966), promovió que el estudiante obtuviera los conocimientos por sí mismo, propuso que el contenido, que iba a ser aprendido, no fuera presentado en su forma final, sino que debía ser descubierto por el dicente. En otras palabras, esta teoría promueve que el estudiante construya su propio conocimiento, derivado de su capacidad analítica, teniendo la guía y el acompañamiento del maestro. En contraste con la enseñanza tradicional, o transmisora del conocimiento, donde el docente pretendía que la información fuera simplemente recibida por los estudiantes. 


\section{Relación entre la mayéutica y la teoría del aprendizaje por descubrimiento}

El paralelismo entre la mayéutica y el constructivismo, especialmente en la Teoría del Aprendizaje por descubrimiento de Jerome Bruner, es bastante amplio. Inicialmente se puede notar que los roles entre el maestro y el alumno guardan las mismas características, debido que, en ambos casos, el protagonismo lo posee el discípulo, en el sentido que construye su propio conocimiento, analiza, contextualiza las situaciones, resuelve los problemas de acuerdo con sus presaberes, recibiendo la guía y el acompañamiento de su tutor.

Otra de las características que guarda enorme relación es la búsqueda del conocimiento dentro de sí mismo, Sócrates ya lo mencionaba "Conócete a sí mismo", porque sabía el poder que posee cada ser humano de dar a luz su propio conocimiento, tal y como reza el constructivismo cuyo fundamento es precisamente la construcción del propio saber, basado en las propias capacidades; así como la edificación de un mejor ser humano, lo cual es otro aspecto que nos remonta al pensamiento socrático que buscó forjar una mejor sociedad por medio de su ejemplo y con la transmisión de valores éticos.

Bruner (1980), consideró que el ser humano está dotado de capacidad para autorregular su conocimiento; pero esto sería posible si se enfrentaba a situaciones que le hicieran reflexionar; debido a que no existirá comprensión real de las cosas, hasta que el alumno aplique dicho conocimiento en otras situaciones; el aprender implica representar e interpretar la situación, establecer conexiones entre los factores relevantes, seleccionar, aplicar reglas, métodos, y construir sus propias conclusiones. Sócrates por su parte instó de igual manera a la reflexión a sus interlocutores, promoviendo el diálogo y el análisis personal que le hiciera extraer de sí mismo, la respuesta a sus interrogantes, otorgándoles un papel activo en el proceso epistemológico, en la construcción del conocimiento.

\section{Conclusión}

La reflexión es uno de los puntos medulares, en ambas metodologías, debido a que es un acto que demuestra la capacidad innata que posee cada ser humano para acceder al conocimiento, dicho de otra manera, el conocimiento abre sus puertas a todo aquel que desee acceder a él, no solamente a ciertos privilegiados. La capacidad de análisis debe ser fomentada y fortalecida en las instituciones educativas, es el primer paso para transformar las actitudes y como consecuencias la sociedad. Si se necesitan estudiantes que actúen, se debe enseñarles inicialmente a que cuestionen. Dichas propuestas, tuvieron que enfrentarse a otros paradigmas que había que romper, cada cual en su tiempo y espacio, en cuanto que Sócrates, propuso el acto reflexivo en un contexto plagado de sofistas que predicaban ser sabios y poseer el conocimiento, haciendo creer a la sociedad que eran los portadores de la sabiduría, lo cual desmintió Sócrates, demostrando que todo ser humano es capaz de reflexionar y aprender, de acceder al conocimiento por sí mismos; de igual manera el constructivismo sale a la luz en un contexto en donde los métodos tradicionales de aprendizaje, habían colocado en un podio al docente, en donde el único que poseía el conocimiento era él, dándole menos valor a las propuestas que podía brindar el alumno, lo cual desmitificó Bruner con la teoría del aprendizaje por descubrimiento y Sócrates por su parte, con el método mayéutico. 
El docente o maestro, es un puente en ambas posturas, es quien facilitará que el estudiante dé a luz el conocimiento, que explore por sí mismo construyendo su propio aprendizaje. La importancia de adjudicarle este papel al maestro radica en que el estudiante al aceptar una condición como generador de conocimiento es capaz de afrontar diversas situaciones o problemas por sí mismo, es capaz de resolver situaciones propias y no tener que recurrir siempre a la palabra del maestro o el conocimiento del maestro, ni siquiera resolver dichas situaciones como el maestro las enseñó en cuanto que pueden ser contextos diferentes, lo cual es sumamente importante dentro del aprendizaje.

\section{Referencias}

Albarrán Vásquez, M. (2009). Filosofía el hombre, la naturaleza y la sociedad. México: McGraw-Hill.

Bruner, J. (1966). Toward a Theory of instruction. Cambridge, MA: Harvard University Press.

Bruner, J. (1980). Investigación sobre el desarrollo cognitivo. España: Morata.

Bucheti, A. (2008). La actualidad de Aristóteles. Reflexión Académica en Diseño y Comunicación(22), 82-83. Recuperado el 8 de 3 de 2020, de https://dialnet.unirioja.es/servlet/articulo?codigo=205462

Escobar Valenzuela, G. (2011). Filosofía. México: Patria.

Platón. (1988). Diálogos III y V. Madrid: Gredos.

Platón. (1990). Apología de Sócrates. México: Austral.

\section{Sobre el autor}

\section{Axel Hernaldo Aceituno Ramos}

Licenciado en Letras y Filosofía, actualmente estudia la Maestría en Filosofía en la Facultad de Humanidades, en el campus central de la Universidad de San Carlos, labora como docente en el Centro Universitario de Izabal, impartiendo cursos en las carreras de Licenciatura en Pedagogía y Licenciatura en Trabajo Social.

Copyright (c) Axel Hernaldo Aceituno Ramos

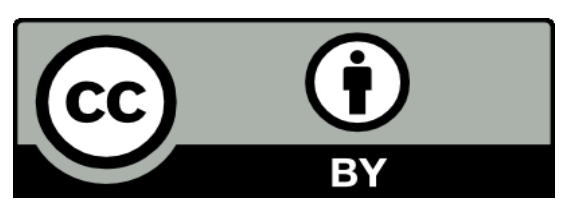

Este texto está protegido por una licencia CreativeCommons 4.0.

Usted es libre para compartir, copiar y redistribuir el material en cualquier medio o formato y adaptar el documento, remezclar, transformar y crear a partir del material para cualquier propósito, incluso comercialmente, siempre que cumpla la condición de atribución: usted debe reconocer el crédito de una obra de manera adecuada, proporcionar un enlace a la licencia, e indicar si se han realizado cambios. Puede hacerlo en cualquier forma razonable, pero no de forma tal que sugiera que tiene el apoyo del licenciante o lo recibe por el uso que hace. 